\title{
Heavy caffeine intake in pregnancy and sudden infant death syndrome
}

\author{
R P K Ford, P J Schluter, E A Mitchell, B J Taylor, R Scragg, A W Stewart, \\ and the New Zealand Cot Death Study Group
}

Community Paediatric Unit, Christchurch R P K Ford

P J Schluter

Department of

Paediatrics, University of Auckland

E A Mitchell

Department of

Paediatrics, University of Otago

B J Taylor

Department of

Epidemiology,

University of Auckland R Scragg

Department of Biostatistics,

University of Auckland

A W Stewart

Other members of the New Zealand Cot Death Study Group are:

E M Allen

J M D Thompson

$S$ Williams

D M J Barry

D M O Becroft

I B Hassall

A P Roberts

Correspondence to:

Dr R P K Ford, Community Paediatric Unit, Community Child and Family Service, PO Box 25-265,

Christchurch, New Zealand.

Accepted 22 October 1997

\begin{abstract}
Aims-To examine the association between maternal caffeine consumption during pregnancy and the risk of sudden infant death syndrome (SIDS).

Methods-A nationwide case-control study surveying parents of 393 SIDS victims and parents of 1592 control infants. Caffeine consumption in each of the first and third trimesters was estimated by questionnaire. Heavy caffeine intake was defined as $400 \mathrm{mg} /$ day or more (equivalent to four or more cups of coffee per day).

Results-Infants whose mothers had heavy caffeine consumption throughout their pregnancy had a significantly increased risk for SIDS (odds ratio 1.65; $95 \%$ confidence interval 1.15 to 2.35 ) after adjusting for likely confounding factors. Conclusion-Caffeine intake has been associated with fetal harm and now SIDS. Reducing heavy caffeine intake during pregnancy could be another way to lessen the risk of SIDS. This needs confirmation by others.
\end{abstract}

(Arch Dis Child 1998;78:9-13)

Keywords: SIDS; caffeine; pregnancy

We have examined the hypothesis that mothers' caffeine consumption during pregnancy might cause the infant to be more vulnerable to the sudden infant death syndrome (SIDS or cot death). To our knowledge, there are no previous reports on such a relationship.

Caffeine is a very commonly consumed licit stimulant drug. ${ }^{1}$ It crosses the placental barrier so exposing the growing fetus to maternally ingested caffeine. The effect of this is potentiated in the last trimester when caffeine elimination from the mother is reduced about threefold. ${ }^{2}{ }^{3}$ Caffeine intake has been associated with low birth weight and spontaneous abortion in some studies. ${ }^{4-7}$ Also, caffeine withdrawal at birth can induce clinical effects, including apnoea, in newborns. ${ }^{89}$ Overall, it is evident that high levels of caffeine (more than $300 \mathrm{mg} /$ day, equivalent to three or more cups of coffee) during pregnancy are potentially harmful. ${ }^{1}$ We postulated that maternal caffeine consumption during pregnancy might contribute to the risk of SIDS.

\section{Methods}

The New Zealand Cot Death Study, a case-control design, was completed over a three year period, 1987-90. ${ }^{10}{ }^{11}$ There were 485 SIDS deaths compared with a stratified random selection of 1800 control infants. Data, ascertained from an interview based questionnaire, were obtained for $393(81.0 \%)$ of the cases and $1592(88.4 \%)$ of controls. For control infants, a nominated date and time was used to base interview questions on which ensured a similar age distribution to that expected for cases. The median time between the SIDS day of death and the interview date was 28 days $\left(Q_{1}=20\right.$ days, $Q_{3}=44$ days $)$ for parents of SIDS infants while the median time between the nominated date and the interview date was two days $\left(Q_{1}=1\right.$ day, $Q_{3}=6$ days) for parents of control infants.

Caffeine consumption was estimated by asking how many cups/glasses of tea, caffeinated coffee, and cola drinks they had been taking each day or each week during the first and third trimesters of their pregnancy. Conversion factors used were: cup of coffee $100 \mathrm{mg}$, cup of tea $40 \mathrm{mg}$, and a glass of cola $40 \mathrm{mg} .{ }^{12}$ Caffeine intake was divided into four categories: small, 0-99 mg/day; light, 100-199 mg/day; moderate, $200-399 \mathrm{mg} /$ day; and heavy, $400 \mathrm{mg}$ /day or more. ${ }^{5}$ This can be translated into equivalent cups of coffee: less than one cup/day; one cup but less than two cups; two cups but less than four cups; and four cups/day or more.

Logistic regressions were used to examine the relationship between maternal caffeine consumption and SIDS. All multivariate logistic regressions were controlled for the confounding factors listed in the appendix by simultaneously incorporating them into the logistic model. These confounding factors have been defined and discussed previously. ${ }^{10}{ }^{11}$ Investigation into variable interactions in the logistic model was conducted using the method of Hosmer and Lemeshow. ${ }^{13}$ The degree of agreement between caffeine consumed during the first and third trimesters was measured and tested using the $\kappa$ statistic. ${ }^{14}$ 
Table 1 Daily caffeine consumption in the first and third trimester and the associated risk of SIDS

\begin{tabular}{|c|c|c|c|}
\hline $\begin{array}{l}\text { Caffeine consumption } \\
\text { (mg/day) }\end{array}$ & $\begin{array}{l}\text { No (\%) SIDS } \\
\text { infants }\end{array}$ & $\begin{array}{l}\text { No (\%) control } \\
\text { infants }\end{array}$ & $\begin{array}{l}\text { OR }(95 \% \text { CI) } \\
\text { unadjusted } t\end{array}$ \\
\hline \multicolumn{4}{|l|}{ First trimester } \\
\hline $0-99$ & $108(28.7)$ & $526(33.3)$ & 1.00 \\
\hline $100-199$ & $67(17.8)$ & $333(21.1)$ & 0.95 (0.68 to 1.33$)$ \\
\hline $200-399$ & $88(23.3)$ & $434(27.5)$ & $0.96(0.71$ to 1.31$)$ \\
\hline$\geqslant 400$ & $114(30.2)$ & $288(18.2)$ & $1.90(1.41 \text { to } 2.57)^{\star \star \star}$ \\
\hline \multicolumn{4}{|l|}{ Third trimester } \\
\hline $0-99$ & 109 (28.9) & $510(32.3)$ & 1.00 \\
\hline $100-199$ & $68(18.0)$ & $337(21.3)$ & 0.93 (0.66 to 1.29$)$ \\
\hline $200-399$ & $82(21.8)$ & $456(28.8)$ & $0.83(0.61$ to 1.14$)$ \\
\hline$\geqslant 400$ & $118(31.3)$ & $278(17.6)$ & $1.97(1.46 \text { to } 2.66)^{\star \star \star}$ \\
\hline
\end{tabular}

\section{Results}

SOURCES OF CAFFEINE AND PATTERNS OF CONSUMPTION

The amounts of caffeine consumed by the types of beverages taken was examined for the control mothers $(n=1581)$. In the smallest caffeine category (0-99 mg/day), 225 (44\%) consumed no caffeine at all. The average weekly beverage consumption of the remaining mothers in this category was: $152(30 \%)$ drank tea only (10 cups/week); six (1\%) drank coffee only (3.0 cups/week); 48 (9\%) drank cola only (4.5 cups/week); and 79 (15\%) had a combination of drinks at rates 8.5 cups/week for tea, 0.5 cups/week for coffee, and 1.0 glass/week for cola. By contrast, the average daily pattern of consumption for mothers $(n=278)$ in the heaviest caffeine category $(\geqslant 400 \mathrm{mg} /$ day) was: $24(9 \%)$ drank tea only (14 cups/day); 59 (21\%) drank coffee only (7.0 cups/day); and two drank cola only (12 and 15 glasses/day). The other mothers $(69 \%)$ in this category consumed daily, on average: four cups of tea; four cups of coffee; and one glass of cola.

\section{SIDS RISK WITH CAFFEINE INTAKE}

The number (and percentage) of both case and control mothers by category of daily caffeine consumption in the first and third trimester is given in table 1. More case mothers were found in the heavy caffeine group compared with control mothers for both the first trimester $(30 \% v 18 \%$, respectively) and third trimester (31\% v 18\%, respectively). From table 1, for both first or third trimester measurements, it is evident that the relative risk for SIDS increased with high levels of caffeine consumption $(\geqslant 400$ $\mathrm{mg}$ /day), while the three lesser caffeine con- sumption categorisations had relative risks that were virtually indistinguishable from each other.

Using the rationale of Hosmer and Lemeshow, the similarity in relative risk estimates for caffeine categories 0-99, 100-199, and 200$399 \mathrm{mg} /$ day suggest that they should be combined. ${ }^{13}$ Mothers were thus dichotomised into groups based on non-heavy caffeine consumption (0-399 mg/day) and heavy caffeine consumption ( $\geqslant 400 \mathrm{mg} /$ day) over the two trimester measurements, the former being treated as the reference group. Moreover, a measure of caffeine intake over pregnancy was derived by defining mothers that recorded heavy caffeine consumption in both the first and third trimesters as being heavy caffeine consumers, while all other mothers were designated as having non-heavy caffeine consumption throughout pregnancy. From this definition it was apparent (table 2) that more SIDS mothers consumed heavy caffeine throughout pregnancy than their control counterparts ( $28.1 \%$ v $14.0 \%$, respectively).

Analysis of the first trimester, third trimester, and all pregnancy dichotomous caffeine groups showed that the relative risk for SIDS was increased for those infants with mothers in the heavy caffeine group ( $\geqslant 400 \mathrm{mg} /$ day), table 2 . Mothers in the heavy caffeine group at the first trimester had infants with an increased risk for SIDS of 1.95 (95\% confidence interval (CI) 1.51 to 2.52 ) relative to the non-heavy group (0-399 mg/day). This risk increased for those infants with mothers in the heavy caffeine group at the third trimester (odds ratio (OR) $2.14 ; 95 \%$ CI 1.66 to 2.76 ) and increased again when mothers consumed heavy caffeine throughout pregnancy (OR 2.42; 95\% CI 1.85 to 3.15). This association was maintained, albeit with reduced risk, after adjusting for likely confounders: the first trimester relative risk was 1.30 (95\% CI 0.92 to 1.82 ); the third trimester relative risk equalled 1.46 (95\% CI 1.05 to 2.05); and the relative risk with heavy caffeine throughout pregnancy was $1.65(95 \%$ CI 1.15 to 2.36 ).

It is also apparent from table 2 that SIDS mothers were not only consuming heavy caffeine at a higher rate, but they were more consistent in their heavy caffeine consumption over pregnancy. Of the 114 SIDS mothers in the heavy caffeine group at the first trimester,

Table 2 Relative risk of SIDS for the dichotomised daily caffeine consumption variable in the first and third trimesters, and all pregnancy

\begin{tabular}{|c|c|c|c|c|}
\hline Caffeine consumption (mg/day) & $\begin{array}{l}\text { No (\%) SIDS } \\
\text { infants }\end{array}$ & $\begin{array}{l}\text { No (\%) control } \\
\text { infants }\end{array}$ & OR $(95 \%$ CI) unadjusted $t$ & OR $(95 \%$ CI) adjusted $\ddagger$ \\
\hline \multicolumn{5}{|l|}{ First trimester } \\
\hline Non-heavy (0-399) & $263(69.8)$ & $1293(81.8)$ & 1.00 & 1.00 \\
\hline Heavy $(\geqslant 400)$ & $114(30.2)$ & $288(18.2)$ & $1.95(1.51 \text { to } 2.52)^{\star \star \star}$ & $1.30(0.92$ to 1.82$)$ \\
\hline \multicolumn{5}{|l|}{ Third trimester } \\
\hline Non-heavy (0-399) & $259(68.7)$ & $1303(82.4)$ & 1.00 & 1.00 \\
\hline Heavy $(\geqslant 400)$ & $118(31.3)$ & $278(17.6)$ & $2.14(1.66 \text { to } 2.76)^{\star \star \star}$ & $1.46(1.05 \text { to } 2.05)^{\star}$ \\
\hline \multicolumn{5}{|c|}{ All pregnancy (both first and third trimesters) } \\
\hline Non-heavy $(0-399)$ & $271(71.9)$ & $1359(86.0)$ & 1.00 & 1.00 \\
\hline Heavy $(\geqslant 400)$ & $106(28.1)$ & $222(14.0)$ & $2.42(1.85 \text { to } 3.15)^{\star \star \star}$ & $1.65(1.15 \text { to } 2.36)^{\star \star}$ \\
\hline
\end{tabular}

†Adjusted for infants' age only.

$\ddagger$ Adjusted for confounding factors listed in the appendix. Wald statistic $\mathrm{p}$ values: ${ }^{\star} \mathrm{p}<0.05,{ }^{\star \star} \mathrm{p}<0.01,{ }^{\star \star \star} \mathrm{p}<0.001$. 
106 (93.0\%) continued consuming heavy caffeine during the third trimester. By comparison, 222 of the $288(77.1 \%)$ control mothers maintained this level of heavy caffeine consumption over this time. Similarly, of those mothers consuming heavy caffeine in the third trimester, $89.8 \%$ of SIDS mothers and $79.9 \%$ control mothers, were consuming heavy caffeine in the first trimester. This consistency in caffeine consumption for SIDS mothers between trimesters is reflected in a higher estimated value of agreement $\left(\kappa_{\text {SIDS }}=0.88\right.$, $\mathrm{SE}=0.03)$ compared with the control mothers $\left(\kappa_{\text {control }}=0.74, \mathrm{SE}=0.02\right)$, a difference that was statistically significant $\left(\chi^{2}=15.46, \mathrm{df}=1\right.$, $\mathrm{p}<0.001$ ).

Stepwise logistic regression was performed on the control mothers data to identify factors that might be closely associated with heavy caffeine consumption throughout pregnancy. Three factors were identified and are reported in decreasing strength of association: maternal smoking; young mothers; and mothers finishing school at a young age. Although not identified in this fashion, the method of infant feeding was also investigated.

Heavy caffeine consumption over pregnancy appeared to have a separate and different effect on the risk of SIDS from maternal smoking status as no evidence for an interaction was identified $(\chi=0.03, \mathrm{df}=1, \mathrm{p}=0.86)$. Likewise, no interaction was identified with young mothers $\left(\chi^{2}=0.02, \mathrm{df}=1, \mathrm{p}=0.90\right)$, mothers finishing school at a young age $\left(\chi^{2}=2.26, \mathrm{df}=1, \mathrm{p}=0.13\right)$, and bottle feeding mothers $(\chi=0.68, \mathrm{df}=1$, $\mathrm{p}=0.41)$. Non-significant interactions also resulted when these factors were considered with heavy caffeine consumption over the first and third trimesters separately.

POPULATION ATTRIBUTABLE RISK

An estimate was made of the proportion of SIDS cases that could be attributed to heavy maternal caffeine intake: throughout pregnancy using the exposure of $14.0 \%$ and unadjusted OR of 2.42 , the population attributable risk was $17 \%$ (95\% CI 11 to 23 ).

\section{Discussion}

Previous reports indicate that moderate to heavy caffeine exposure to the fetus has a potential harmful effect. ${ }^{12457}$ We have found that a heavy consumption of caffeine $(\geqslant 400$ $\mathrm{mg}$ /day), equivalent to four or more cups of coffee a day, was significantly associated with an increased the risk for SIDS after adjustment for likely confounders.

A deficiency of this retrospective epidemiological study, common with all such studies, is that daily caffeine intake was determined from questionnaire response. Individual variations in concentrations and volumes of the caffeine beverages consumed coupled with the mother's memory recall of consumption rates means that caffeine dose can only be approximately ascertained. However, caffeine is a licit and socially acceptable stimulant and there should be no reason for under reporting. Furthermore, to our knowledge, there have been no

\section{Key messages}

- Heavy maternal caffeine consumption throughout pregnancy was significantly associated with an increased relative risk for SIDS (OR 1.65) after adjustment for confounders

- Caffeine consumption of $\geqslant 400 \mathrm{mg} /$ day (equivalent to four or more cups of coffee per day) was defined to be heavy

- Caffeine consumption is a modifiable behaviour

- Reducing heavy caffeine intake during pregnancy may decrease the risk of SIDS

previous reports of caffeine intake being related to SIDS so self reports of caffeinated drink consumption should not have been biased by selective recall. We believe, therefore, that the caffeine measurements derived from the questionnaire responses of this randomised study adequately identified the heavy caffeine consumers.

It has been recognised that misclassification of a confounding factor leads to a partial loss of the ability for that confounding factor to be controlled thereby potentially distorting any estimated association. ${ }^{15}{ }^{16}$ Recall bias in the reporting of variables such as maternal smoking, mother's age, or maternal alcohol consumption may thus affect the significance of the findings reported in this paper. However, with the careful elicitation and categorisation of confounding factors used in this study, we believe that any effect due to this phenomenon will be small.

For those with a heavy intake of caffeine, the main source was from coffee. Heavy caffeine consumption throughout pregnancy was found in $14 \%$ of the control mothers, half that of the SIDS mothers $(28 \%)$. Although heavy caffeine consumers were also more likely to smoke, over $40 \%$ of such consumers were non-smokers. Subsequent multivariate analyses controlling for smoking, among other factors, revealed that the effect of heavy caffeine was additional to the effect of smoking, and that no significant interaction effect between heavy caffeine consumption and smoking was evident.

A possible explanation for fetal caffeine exposure causing an increased risk for SIDS is through its respiratory stimulant effect. Caffeine is commonly used for this reason to treat of apnoea of prematurity as it induces a significant increase in ventilation. ${ }^{17}{ }^{18}$ Maternal caffeine intake during pregnancy has been associated with increased episodes of central apnoea in infants. ${ }^{8}$ Irritability, jitters, and vomiting following heavy caffeine withdrawal have also been documented. ${ }^{9}$ It is possible that the fetal respiratory centre could be altered in the presence of high caffeine concentrations. The subsequent withdrawal of caffeine after birth might then leave the infant with an inadequate respiratory drive when later exposed to respiratory stressors.

Chronic caffeine exposure increases the number of adenosine receptor sites in the 
brainstem for which caffeine is a competitive antagonist. ${ }^{19}$ Adenosine is produced during episodes of severe hypoxia and can induce respiratory depression in newborn animals. ${ }^{20}$ Therefore, prior caffeine exposure in utero may be a cause of increased vulnerability to the infant who is later exposed to episodes of hypoxia. ${ }^{8}$

We have found that the fetus when exposed to high levels of caffeine in utero subsequently has a significantly increased risk for SIDS. The importance of this finding is that drinking coffee, tea and cola is a common and easily modifiable behaviour. Mothers, therefore, have the opportunity to alter this risk factor. Reduction of heavy caffeine consumption during pregnancy could be another way to decrease the risk of SIDS, with nearly a sixth of infants so exposed. As this is the first report of such an association, it should be confirmed by others before reduction in caffeine intake is recommended in pregnancy.

This study was funded by the Health Research Council of New Zealand (HRCNZ)

1 Eskenazi B. Caffeine during pregnancy: grounds for concern? FAMA 1993;270:2973-4.

2 Berger A. Effects of caffeine consumption on pregnancy outcome. F Reprod Med 1988;33:945-56.

3 Parsons WD, Pelletier JG. Delayed elimination of caffeine by women in the last 2 weeks of pregnancy. Can Med Assoc f $1982 ; 127: 377-81$

4 Narod SA, de Sanjose S, Victora C. Coffee during pregnancy: a reproductive hazard? Am f Obstet Gynecol 1991;164:1109-14.

5 McDonald AD, Armstrong BG, Sloan M. Cigarette, alcohol, and coffee consumption and prematurity. Am $\mathcal{F}$ Public Health 1992;82:87-90.

6 Armstrong BG, McDonald AD, Sloan M. Cigarette, alcohol, and coffee consumption and spontaneous abortion. Am $\mathcal{F}$ Public Health 1992;82:85-87.

7 Infante-Rivard C, Fernandez A, Gauthier R, et al. Fetal loss associated with caffeine intake before and during pregassociated with caffeine intake
nancy. $\mathcal{F} A M A$ 1993;270:2940-3.

8 Toubas PL, Duke JC, McCaffree MA, et al. Effects of maternal smoking and caffeine habits on infantile apnea: a retrospective study. Pediatrics 1986;78:159-63.

9 McGowan JD, Altman RE, Kanto WP. Neonatal withdrawal symptoms after chronic maternal ingestion of caffeine. South Med $\mathscr{f}$ 1988;81:1092-4.

10 Mitchell EA, Scragg R, Stewart AW, et al. Results from the first year of the New Zealand Cot Death Study. $N Z M e d f$ 1991;104:71-6.

11 Mitchell EA, Taylor BJ, Ford RPK, et al. Four modifiable and other major risk factors for cot death: the New Zealand study. F Paediatr Child Health 1992;28(suppl 1):S3-8.

12 Bunker ML, McWilliams M. Caffeine content of common beverages. F Am Diet Assoc 1979;74:28-32.

13 Hosmer DW, Lemeshow S. Applied logistic regression. New York: Wiley, 1989.

14 Fleiss LJ. Statistical methods for rates and proportions. 2nd Ed. New York: Wiley, 1981 .

15 Greenland S, Robins J. The effect of misclassification in the presence of covariates. Am f Epidemiol 1980;112:564-9

16 Greenland S, Robins J. Invited commentary: ecologic studies-biases, misconceptions, and counterexamples. $A m$ f Epidemiol 1994;139:747-60.

17 Scanlon JEM, Chin KC, Morgan MEI, et al. Caffeine or theophylline for neonatal apnoea? Arch Dis Child 1992;67 $425-8$.

18 Aranda JV, Turmen T, Davis J, et al. Effect of caffeine on control of breathing in infantile apnea. F Pediatr 1983;103: 975-8.

19 Biaggioni I, Paul S, Puckett A, et al. Caffeine and theophylline as adenosine receptor antagonists in humans. $f$ Pharmacol Exp Ther 1991;258:588-93.

20 Berne RM, Rubio R, Curnish RR. Release of adenosine from ischemic brain. Circ Res 1974;35:262-3.

21 Lagercrantz H, Yamamoto Y, Fredholm BB, et al. Adenosine analogues depress ventilation in rabbit neonates. Theophylline stimulation of respiration via adenosine receptors? Pediatr Res 1984;18:387-90.

\section{Appendix}

Multivariate logistic regressions were controlled for the following confounding factors:
(A) Selection variables: infant age at death/ nominated date (weeks), region (Auckland, Napier, Hamilton/Rotorua, Hutt/Wellington, Christchurch, Dunedin/Invercargill), time of death/nominated time of day (00:00-05:59, 06:00-11:59,12:00-17:59, 18:00-23:59), season of death/nominated date (January/ February, December/March, November/April, October/May, September/June, August/July).

(B) Sociodemographic details: highest occupational status of mother or father (I/II, III/IV, $\mathrm{V} / \mathrm{VI} /$ other), marital status of mother (married, non-married), age mother left school $(<15$, $15-17, \geqslant 18$ years)

(C) Pregnancy details: age of mother at infant's birth $(<20,20-24,25-29, \geqslant 30$ years $)$, number of previous pregnancies (none, $1,2,3, \geqslant 4$ ), maternal smoking in last two weeks (no, yes), mother's alcohol intake over the last month (mg per month), months pregnant when first attended antenatal clinic $(0-3, \geqslant 4$ months), attendance at antenatal classes (yes, no).

(D) Infant details: infant sex (female, male), infant birth weight $(<2500,2500-2999,3000-$ $3499, \geqslant 3500 \mathrm{~g})$, gestation $(28-33,34-37, \geqslant 38$ weeks), ethnic group (Maori, Pacific Islander, European/other), twin birth (no, yes).

(E) Postnatal factors: infant admitted to neonatal intensive care unit (no, yes), main type of milk fed to infant in the first four weeks (breast, bottle), infant sleep position at death/ nominated sleep (non-prone, prone), and infant bed sharing with another person at death/nominated sleep (no, yes).

\section{Commentary}

The New Zealand Cot Death Study Group is appropriately cautious about the strength of the evidence from their study, which suggests that heavy maternal caffeine intake in pregnancy is a cause of SIDS. This is the first report of such an association. It needs to be tested in other settings for the result to convince.

Data were obtained by retrospective interview from 393 cases and 1592 controls. The questionnaire was extensive-note the long list of confounding variables for which adjustment is made. The sceptic would suspect that this association is one trawled from a 'fishing expedition'. It is often possible to produce a plausible mechanism to explain a link afterwards.

The authors use four groups for caffeine consumption and show that it is only in the highest group that the risk of SIDS is raised. Thus, there is no dose-response relationship, rather a threshold effect. They then group the three lowest categories for further analysis. This has the effect of making the statistical significance of the association more impressive. Whether it would in replications of the study is questionable. Three related issues: it is often helpful to separate the completely unexposed group, who might behave differently in other ways; an analysis with consumption as a continuous variable might be more powerful, but would produce a less impressive result in this study; it would also be useful to see analyses according to source of caffeine. 
Adjustment for the many confounding variables reduces the odds ratio for heavy caffeine consumption throughout pregnancy from 2.42 to 1.65 , halving the effect. This shows the strong effect of the confounders and raises the anxiety that, had they been measured more accurately, the effect would have disappeared. This worry is heightened when we read of the strength of association between high caffeine exposure and several of the confounders.

The odds ratio, while statistically significant, is still not large enough to exclude chance as another explanation. The authors helpfully estimate the proportion of SIDS cases that could be attributed to high caffeine consumption, though before adjustment. It is not large. They discuss recall bias.

But it is too easy to sit back and criticise those who have gone out, got their hands dirty, and collected interesting data on an important subject. They are to be commended and their association deserves to be tested elsewhere.

CLIVE OSMOND MRC Environmental Epidemiology Unit, University of Southampton, Southampton General Hospital, Southampton SO16 6YD 